\title{
MODELLING OF FALLING FILM REACTORS
}

\author{
B. Dabir ${ }^{1}$, M.R. Riazi ${ }^{2 *}$ and H.R. Davoudirad ${ }^{1}$ \\ 1. Chemical Engineering Dept., Amir-Kabir University of Technology, Tehran, Iran \\ 2. Chemical Engineering Dept., Kuwait Univ., P.O. Box 5969, Safat 13060, Kuwait
}

\begin{abstract}
An improved mathematical model for falling film reactors is presented. Effects of liquid film turbulence, gas phase heat and mass transfer resistances, gas-liquid interfacial drag, exothermic chemical reaction and heat transfer within the system, as well as volatility of liquid film are considered. The model predicts liquid phase chemical conversions and the interfacial temperatures along the reactor length. Model predictions agreed well with data from both laboratory and industrial scale reactors.
\end{abstract}

\section{INTRODUCTION}

Falling film reactors are being widely used for exothermic gas-liquid reactions such as sulfonation or chlorination. In the chemical industry, falling film reactors are used in detergent and wetting/dispersing agents manufacturing plants. Sulfonation of dodecylbenzene (DDB) or linearalkyl-benzene (LAB) by sulfur trioxide $\left(\mathrm{SO}_{3}\right)$ gas are the best examples of reactions occuring in these industries.

Accurate modeling of such reactors would result in economic and optimum design and operation of the reactor. Previous mathematical models for falling film reactors have been proposed by Johnson and Crynes (1974), Davis et al. (1979) and Gutierrez-Gonzalez et al. (1988). In most of these models simplifying assumptions have been used which make validity of the model questionable. Examples of such assumptions are: reaction occurs only at the gas-liquid interface or mass transfer in the gas phase is the controlling step in the process.

Gonzalez et al. (1988) reported some 40 new experimental data on sulfonation of DDB by $\mathrm{SO}_{3}$ gas using a laboratory falling film reactor. They also developed a mathematical model for calculation of the degree of conversion of DDB along the reactor length by implementing the most realistic assumptions. However, the main deficiency of their model was to use several numerical correcting factors for estimation of the friction factor at the gas-liquid interface as well as heat and mass transfer coefficients in the gas phase. These numerical constants were determined by minimizing the average deviation between model predictions and experimental data. Introducing such correcting factors makes application of the model suitable only for the data used to obtain the model parameters. The purpose of this paper is to introduce an improved and general model for falling film reactors.

The model proposed in this paper is appropriate for both laminar and turbulent films and it considers effects of wavy film flow by using eddy diffusivity parameter. The eddy diffusivity model proposed by Lamourelle and Sandall for the outer region modified by van Driest model for the region near the wall have been used in the model. Effects of interfacial drag at the gas-liquid interface and the gas-phase heat and mass transfer resistances and liquid volatility have been also considered in the proposed model. The model predicts conversions, gas-liquid interface temperature and liquid

\footnotetext{
* Author to whom all correspondence should be addressed.
} 
film thickness along the reactor length and it is applicable to any falling film reactor. Knowledge of temperature distribution alnog the reactor is important for the product quality control, since for highly exothermic reactions under certain conditions degredation of the products may occur.

\section{PROPOSED MATHEMATICAL MODEL}

Consider a system in which a liquid initially free of the absorbing spieces at $z=0$ flows down the surface of a vertical and impermeable wall under the influence of gravity. The absorbing spieces are absorbed by the liquid where it undergoes an irreversible chemical reaction. It is assumed that the gas phase concentration of absorbing spieces is constant. The steady state mass balances on the absorbing spieces $(A)$ in the liquid phase is:

$$
u \frac{\partial C_{A}}{\partial z}=\frac{\partial}{\partial y}\left[\left(D_{A}+\varepsilon_{D}\right) \frac{\partial C_{A}}{\partial y}\right]-r
$$

where $y$ varies from $y=0$ (at the wall surface) to $y=\delta$ (at the liquid free surface) in which $\delta$ is the liquid film thickness. $r$ is the rate of reaction, $C_{A}$ is molar concentration of absorbing spieces in liquid film and $\varepsilon_{D}$ is eddy diffusivity. Equation 1 can also be applied to reactant $B$ in the liquid phase which reacts with $A$ to form the product. The axial liquid velocity, $u$, can be found from the momentum equation after neglecting the pressure gradient and axial terms:

$$
u=\int_{0}^{y} \frac{g(\delta-y)+J \tau_{i} / \rho}{\nu+\varepsilon_{M}} d y
$$

where $\tau_{i}$ is the interfacial shear stress at the gas-liquid interface. For cocurrent systems $J=+1$ and for countercurrent systems $J=-1$. Calculation of $\tau_{i}$ is discussed by Riazi and Faghri (1986) and it is based on the relations proposed by Henstock and Hanratty (1976). Riazi and Faghri (1986) have shown that when gas flow is turbulent as in most cases for falling film reactors, effects of interfacial drag cannot be neglected. For laminar liquid films eq. 2 reduces to:

$$
u=\frac{g}{\nu}\left(\delta y-\frac{y^{2}}{2}\right)+\frac{J \tau_{i} y}{\mu}
$$

It can be shown that $\delta$ can be calculated by trial-and-error procedure from the following equation:

$$
\delta=\left(\frac{\Gamma}{\delta / 3 \mu+J \tau_{i} / 2 \mu}\right)^{\frac{1}{2}}
$$

In exothermic reactions large amount of heat may be released and energy equation in addition to mass and momentum equations is needed.

$$
u \frac{\partial T}{\partial z}=\frac{\partial}{\partial y}\left[\left(\alpha+\varepsilon_{H}\right) \frac{\partial T}{\partial y}\right]+\left(\frac{\Delta H_{R}}{\rho C_{p}}\right) r
$$

In order to proceed to solve eqs. 1,2 and 5 for turbulent liquid films, it is necessary to introduce some empirical profiles for $\varepsilon_{M}, \varepsilon_{H}$ and $\varepsilon_{D}$. As discussed by Gonzalez et al. (1988), even if the liquid film is laminar due to the high Schmidt number and wavy film flow, $\varepsilon_{D}$ cannot be neglected. Accurate specifications of the eddy diffusivity close to the wall and also close to the free surface are much more important than in the middle of the film due to low resistances in the central region. In our model we use eddy viscosity model proposed by van Driest (1956) for the region near the wall modified for outer region of the film by use of an eddy diffusivity deduced from gas absorbtion measurements as given by Lamourelle and Sandall (1972). From van Driest model we can show that:

$$
\varepsilon_{D}=\frac{-\nu+\sqrt{\nu^{2}+4 L^{\prime 2}+4 L^{\prime 2}(\delta-y) g}}{2}
$$

where $L^{\prime}$ is the Prandtl mixing length and is given by:

$$
L^{\prime}=0.4 y\left[1-\exp \left(-\frac{y \sqrt{g \delta}}{26 \nu}\right)\right]
$$


By combining the Lamourelle and Sandall relation for $\varepsilon_{D}$ at $25^{\circ} \mathrm{C}$ with effect of temperature on $\varepsilon_{D}$ as proposed by Levich (1962) we can get:

$$
\frac{\varepsilon_{D}}{\nu}=6.4 \times 10^{-4} \frac{g \rho}{g_{c} \sigma} R e^{1.678}(\delta-y)^{2}
$$

where $R e$ is the Reynolds number for the liquid film $(R e=4 \Gamma / \mu)$. For turbulent liquid films we may assume that $\varepsilon_{M}=\varepsilon_{H}=\varepsilon_{D}$ where all three eddy parameters can be calculated from eqs. 6 and 8. But if the liquid film is laminar then $\varepsilon_{M}=\varepsilon_{H}=0$ and $\varepsilon_{D}$ is calculated from eq. 6 for region near the wall $(y / \delta \leq 0.6)$ or from eq. 8 for region near the liquid surface.

Solution of eqs. 1 and 5 requires appropriate boundary conditions. These conditions are:

$$
\begin{array}{cccccc}
\text { at } & z=0 & C_{A}=0 & C_{B}=C_{B}^{\circ} & \text { and } & T=T^{\circ} \\
\text { at } & y=0 & \frac{\partial C_{A}}{\partial y}=0 & \frac{\partial C_{B}}{\partial y}=0 & \text { and } & K_{L} \frac{\partial T}{\partial y}=U\left(T_{y=0}-T_{R}\right) \\
\text { at } & y=\delta & \frac{\partial C_{A}}{\partial y}=\frac{k_{G} P}{D_{A} R T}\left(y_{A}-y_{A}^{*}\right) & \frac{\partial C_{B}}{\partial y}=-\frac{k_{G} P_{B}^{*}}{D_{B} R T} \quad \text { and } & \frac{\partial T}{\partial y}=\frac{h_{G}}{K_{L}}\left(T_{G}-T_{y=\delta}\right)-\frac{k_{G} P_{B}^{*} \lambda}{K_{L} k T}
\end{array}
$$

In the above equations, $T_{R}$ is the temperature of the refrigerated water used for cooling of the wall to remove the heat released from the reaction. $U$ is the overall heat transfer coefficient for cooling water and liquid film system. Volatility of liquid film is considered in the boundary conditions given at $y=\delta$. For non-volatile liquids such as DDB the vapor pressure, $P_{B}^{*}$, is almost zero at working temperatures. $k_{G}$ and $\mathrm{h}_{G}$ are the gas phase mass and heat transfer coefficients, respectively. $y_{A}$ is mole fraction of absorbing spieces in the gas phase and $y_{A}^{*}$ is the mole fraction in equilibrium with liquid and it can be estimated through Henry's law for the case of $\mathrm{SO}_{3}$ gas. As discussed by Riazi (1986) the effect of gas-phase heat and mass transfer resistances, in general, cannot be neglected in gas absorption with chemical reaction processes. $k_{G}$ and $h_{G}$ may be calculated from standard correlations for the Sherwood and Nusselt numbers:

$$
\begin{aligned}
& S h_{G}=0.046\left(R e_{G}\right)^{0.83}\left(S c_{G}\right)^{0.44} \\
& N u_{G}=0.046\left(R e_{G}\right)^{0.8}\left(P r_{G}\right)^{0.35}
\end{aligned}
$$

To solve partial differential eqs. 1 and 5 , first they were converted into dimensionless forms together with their corresponding boundary conditions. Then, they were put in a finite difference form using implicit scheme which yielded a three-diagonal matrix. 400 increments were chosen in $y / \delta$ direction which varied from 0 to 1 and using a step-by-step advancing technique, concentration $C_{A}$ and temperature, $T$, were calculated at different values of $z$.

\section{EVALUATION OF PROPOSED MODEL}

As mentioned earlier laboratory data obtained by Gonzalez et al. (1988) on sulfonation of DDB to dodecylbenzenesulfonic acid (DDBS) have been used to evaluate the proposed model. If we show $\mathrm{SO}_{3}$ by $\mathrm{A}$ and $\mathrm{DDB}$ by $\mathrm{B}$, then the rate of reaction is $r=k C_{A} C_{B}$ and eq. 1 should be applied once to component $A$ and once to component $B$. Necessary information on the rate constant of the reaction and physiochemical properties of compounds is provided by Gonzalez et el (1988). Value of $U$ for the system studied here was taken from Ludwig (1983) as $0.4 \mathrm{kcal} / \mathrm{m}^{2} \mathrm{sK}$. Diffusion coefficients in liquids were calculated from Wilke-Chang correlation with the correction term for the effect of concentration as discussed by Reid et al.(1987).

Gonzalez and coworkers reported 40 data points on conversion of DDB to DDBS at reactor length of $0.4,0.973$ and $2.0 \mathrm{~m}$ measured in their laboratory and they are given in Table $1 . \mathrm{SO}_{3} / \mathrm{DDB}$ mole ratios were varied between 1.0 and 1.15 while $\mathrm{SO}_{3}$ mole fraction in the gas phase varied from 0.04 to 0.12 . Degree of conversion of DDB to DDBS varied from 70.2 to $93.5 \%$. Predicted conversions from proposed model and deviation from experimental values are also given in Table 1. The overall average deviations between predicted conversions and experimental values were $7 \%$. However, some of data reported by Gonzalez et al. (1988) cannot be trusted. For example, they reported conversion of $87.3 \%$ at reactor length of $0.973 \mathrm{~m}$ (no. 11 in Table 1) and under the same conditions, at length of $2 \mathrm{~m}$ (no. 31) the conversion was reduced to $84.6 \%$ while the conversion should increase with reactor length. 
Table 1. Evaluation of model predictions with laboratory data

\begin{tabular}{|c|c|c|c|c|c|c|c|c|c|c|c|c|c|}
\hline No & $\begin{array}{c}\text { Rea- } \\
\text { ctor } \\
\text { length, } \\
\mathrm{m}\end{array}$ & $\begin{array}{l}\mathrm{SO}_{3} / \\
\mathrm{DDB}^{\prime} \\
\text { mole } \\
\text { ratio }\end{array}$ & $\begin{array}{l}\mathrm{SO}_{3} \\
\text { mole } \\
\text { frac. } \\
\text { in gas }\end{array}$ & $\begin{array}{c}\text { Exp. } \\
\text { conv. } \\
\%\end{array}$ & $\begin{array}{c}\text { Model } \\
\text { conv. } \\
\%\end{array}$ & $\begin{array}{c}\text { Dev. } \\
\%\end{array}$ & No & $\begin{array}{l}\text { Rea- } \\
\text { ctor } \\
\text { length, } \\
\mathrm{m}\end{array}$ & $\begin{array}{c}\mathrm{SO}_{3} / \\
\mathrm{DDB} \\
\text { mole } \\
\text { ratio }\end{array}$ & $\begin{array}{l}\mathrm{SO}_{3} \\
\text { mole } \\
\text { frac. } \\
\text { in gas }\end{array}$ & $\begin{array}{c}\text { Exp. } \\
\text { Conv. } \\
\%\end{array}$ & $\begin{array}{c}\text { Model } \\
\text { Conv. } \\
\%\end{array}$ & $\begin{array}{c}\text { Dev. } \\
\%\end{array}$ \\
\hline $\begin{array}{l}1 \\
2 \\
3 \\
4 \\
5\end{array}$ & $\begin{array}{l}0.400 \\
0.400 \\
0.400 \\
0.400 \\
0.400\end{array}$ & $\begin{array}{l}1.00 \\
1.00 \\
1.00 \\
1.00 \\
1.00\end{array}$ & $\begin{array}{l}0.04 \\
0.06 \\
0.08 \\
0.10 \\
0.12\end{array}$ & $\begin{array}{l}74.9 \\
76.0 \\
74.2 \\
70.2 \\
73.6\end{array}$ & $\begin{array}{l}66.8 \\
67.9 \\
66.4 \\
64.6 \\
62.9\end{array}$ & $\begin{array}{c}10.8 \\
10.6 \\
10.5 \\
8.0 \\
14.5\end{array}$ & $\begin{array}{l}21 \\
22 \\
23 \\
24 \\
25\end{array}$ & $\begin{array}{l}0.973 \\
0.973 \\
0.973 \\
0.973 \\
0.973\end{array}$ & $\begin{array}{l}1.10 \\
1.10 \\
1.10 \\
1.10 \\
1.10\end{array}$ & $\begin{array}{l}0.04 \\
0.06 \\
0.08 \\
0.10 \\
0.12\end{array}$ & $\begin{array}{l}90.3 \\
87.9 \\
85.9 \\
86.2 \\
83.7\end{array}$ & $\begin{array}{l}92.2 \\
88.8 \\
84.5 \\
80.0 \\
77.1\end{array}$ & $\begin{array}{l}2.0 \\
1.0 \\
1.6 \\
7.0 \\
8.0\end{array}$ \\
\hline $\begin{array}{c}6 \\
7 \\
8 \\
9 \\
10\end{array}$ & $\begin{array}{l}0.400 \\
0.400 \\
0.400 \\
0.400 \\
0.400\end{array}$ & $\begin{array}{l}1.10 \\
1.10 \\
1.10 \\
1.10 \\
1.10\end{array}$ & $\begin{array}{l}0.04 \\
0.06 \\
0.08 \\
0.10 \\
0.12\end{array}$ & $\begin{array}{l}83.7 \\
81.0 \\
80.2 \\
80.5 \\
75.8\end{array}$ & $\begin{array}{l}70.8 \\
70.8 \\
69.8 \\
65.7 \\
63.6\end{array}$ & $\begin{array}{l}15.4 \\
12.6 \\
13.0 \\
18.4 \\
16.1\end{array}$ & $\begin{array}{l}26 \\
27 \\
28 \\
29 \\
30\end{array}$ & $\begin{array}{l}0.973 \\
0.973 \\
0.973 \\
0.973 \\
0.973\end{array}$ & $\begin{array}{l}1.15 \\
1.15 \\
1.15 \\
1.15 \\
1.15\end{array}$ & $\begin{array}{l}0.04 \\
0.06 \\
0.08 \\
0.10 \\
0.12\end{array}$ & $\begin{array}{l}93.5 \\
92.0 \\
93.0 \\
85.0 \\
88.5\end{array}$ & $\begin{array}{l}92.9 \\
89.0 \\
84.1 \\
79.8 \\
76.9\end{array}$ & $\begin{array}{l}0.6 \\
3.0 \\
9.5 \\
6.0 \\
13.0\end{array}$ \\
\hline $\begin{array}{l}11 \\
12 \\
13 \\
14 \\
15\end{array}$ & $\begin{array}{l}0.973 \\
0.973 \\
0.973 \\
0.973 \\
0.973\end{array}$ & $\begin{array}{l}1.00 \\
1.00 \\
1.00 \\
1.00 \\
1.00\end{array}$ & $\begin{array}{l}0.04 \\
0.06 \\
0.08 \\
0.10 \\
0.12\end{array}$ & $\begin{array}{l}87.3 \\
83.9 \\
83.2 \\
79.8 \\
76.4\end{array}$ & $\begin{array}{l}89.0 \\
87.9 \\
84.0 \\
80.3 \\
77.5\end{array}$ & $\begin{array}{l}2.0 \\
5.0 \\
1.0 \\
0.5 \\
1.0\end{array}$ & $\begin{array}{l}31 \\
32 \\
33 \\
34 \\
35\end{array}$ & $\begin{array}{l}2.000 \\
2.000 \\
2.000 \\
2.000 \\
2.000\end{array}$ & $\begin{array}{l}1.00 \\
1.00 \\
1.00 \\
1.00 \\
1.00\end{array}$ & $\begin{array}{l}0.04 \\
0.06 \\
0.08 \\
0.10 \\
0.12\end{array}$ & $\begin{array}{l}84.6 \\
85.2 \\
84.9 \\
79.3 \\
75.2\end{array}$ & $\begin{array}{l}94.8 \\
95.7 \\
94.7 \\
92.3 \\
88.8\end{array}$ & $\begin{array}{l}12.0 \\
12.3 \\
11.0 \\
16.4 \\
18.0\end{array}$ \\
\hline $\begin{array}{l}16 \\
17 \\
18 \\
19 \\
20\end{array}$ & $\begin{array}{l}0.973 \\
0.973 \\
0.973 \\
0.973 \\
0.973\end{array}$ & $\begin{array}{l}1.05 \\
1.05 \\
1.05 \\
1.05 \\
1.05\end{array}$ & $\begin{array}{l}0.04 \\
0.06 \\
0.08 \\
0.10 \\
0.12\end{array}$ & $\begin{array}{l}89.7 \\
87.6 \\
85.1 \\
80.5 \\
83.5\end{array}$ & $\begin{array}{l}91.0 \\
88.7 \\
84.2 \\
80.2 \\
77.3\end{array}$ & $\begin{array}{l}1.4 \\
1.0 \\
1.0 \\
0.3 \\
7.6\end{array}$ & $\begin{array}{l}36 \\
37 \\
38 \\
39 \\
40\end{array}$ & $\begin{array}{l}2.000 \\
2.000 \\
2.000 \\
2.000 \\
2.000\end{array}$ & $\begin{array}{l}1.10 \\
1.10 \\
1.10 \\
1.10 \\
1.10\end{array}$ & $\begin{array}{l}0.04 \\
0.06 \\
0.08 \\
0.10 \\
0.12 \\
\end{array}$ & $\begin{array}{l}93.0 \\
91.4 \\
89.5 \\
86.2 \\
84.6\end{array}$ & $\begin{array}{l}97.1 \\
96.2 \\
93.3 \\
91.0 \\
87.7\end{array}$ & $\begin{array}{l}4.4 \\
5.3 \\
4.3 \\
5.6 \\
3.7\end{array}$ \\
\hline
\end{tabular}

* Experimental data are taken from Gonzalez et al. (1988).

$$
\operatorname{dev} . \%=\left|\frac{\text { predicted value }- \text { exp. value }}{\text { exp. value }}\right| \times 100
$$

Figure 1 shows a graphical comparison between model prediction of conversion and experimental values along the reactor length for the case in which mole fraction of $\mathrm{SO}_{3}$ was 0.08 and $\mathrm{SO}_{3} / \mathrm{DDB}$ mole ratio was 1.1 (no. 8,23 and 38 in Table 1). Example of profile of interfacial temperature versus reactor length is shown in Fig. 2. In the model developed by Gonzalez et al. which used three adjusting parameters obtained from their own data set, average error was $5 \%$. However, due to use of such adjusting parameters their model may fail when it is applied to other systems.

To further evaluate the proposed model data from one detergent manufacturing industry (Pakwash Factory, Saveh, Iran) were used. In this factory LAB is being sulfonated by $\mathrm{SO}_{3}$ gas in a falling film reactor operating at $1.25-1.5 \mathrm{~atm}$ pressure with height of $6.7 \mathrm{~m}$ and conversion of 98 -

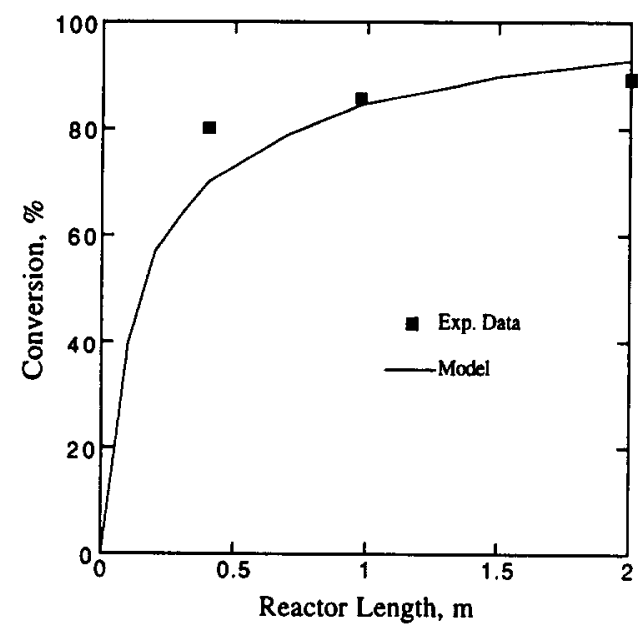

Fig. 1. Prediction of conversion of DDB

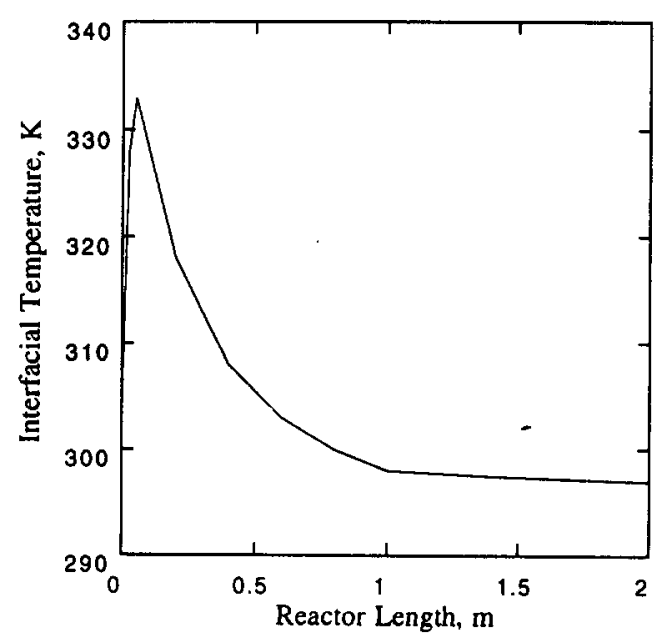

Fig. 2. Calculated interfacial temperature 
$99 \%$. Temperature of inlet liquid $\left(T^{\circ}\right)$ was $303^{\circ} \mathrm{K}$ and temperature of cooling water $\left(T_{R}\right)$ was 293 ${ }^{\circ} \mathrm{K}$. Volumetric flow rate of liquid was $5.5 \times 10^{-4} \mathrm{~m}^{3} / \mathrm{s}$. Mole fraction of $\mathrm{SO}_{3}$ in air was 0.04 and the gas was flowing in the annular space between two vertical tubes. The internal diameter of outer tube was $d_{0}=42 \mathrm{~cm}$ and diameter of internal tube was $d_{i}=11.6 \mathrm{~cm}$. Liquid was flowing on the inner wall of outer tube and on outside wall surface of the inner tube. In using the proposed model for this system an equivalent diameter $\left(d_{e}=d_{0}-d_{i}\right)$ should be used. The proposed model predicted conversion of $99.1 \%$ (versus actual value of $98-99 \%$ ) for this industrial scale reactor. A graphical presentation of model predictions for conversion and liquid film thickness for this industrial reactor is shown in Fig. 3. Concentration profiles in radial direction for $\mathrm{DDB}$ and $\mathrm{SO}_{3}$ at the length of 5.7 $\mathrm{m}$ are shown in Fig. 4. Application of Gonzalez model with previously reported adjusting parameters predicted a conversion of $92 \%$ for the reactor. These evaluations indicate that the proposed model in this paper can predict the behavior of both laboratory and industrial scale falling film reactors with a reasonable degree of accuracy.

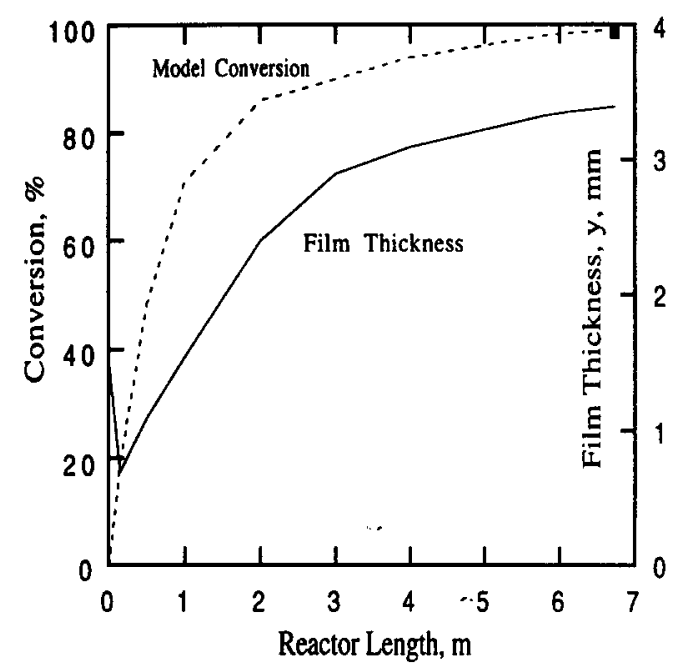

Fig. 3. Model predictions for conversion and film thickness for the industrial reactor. Actual conversion is shown by

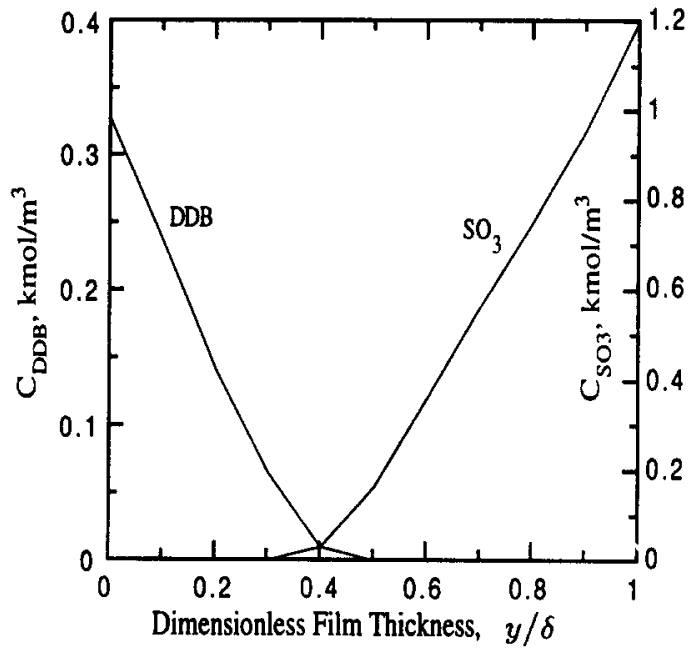

Fig. 4. Concentration radial profiles for the industrial reactor at the length of $5.7 \mathrm{~m}$

\section{CONCLUSIONS}

In this paper a comprehensive model for falling film reactors with an exothermic chemical reaction in the liquid film is presented. The model considers the hydrodynamics, mass and heat transfer processes prevailing in the liquid film. No adjusting parameter is introduced in the proposed model. The model predicts degree of chemical reaction conversion, liquid film thickness and longitudinal temperature along the reactor lenght. Model predictions for the dgree of sulfonation of dodecylbenzene are within $7 \%$ of laboratory data. The model also accurately predicts degree of sulfonation of alkylbenzene in an industrial reactor. The proposed model may be suitable for use in design and operation of industrial falling film reactors.

\section{NOTATION}

$C_{A} \quad=$ molar concentration of absorbing species in liquid film

$C_{B}^{\circ} \quad=$ initial concentration of reactant (DDB) in liquid film

$C_{p} \quad=$ heat capacity of liquid

$D_{A} \quad=$ molecular diffusivity of absorbing gas in liquid film

$d \quad=$ diameter of reactor tube

$g \quad=$ acceleration of gravity

$\Delta H_{R} \quad=$ heat of reaction 
$h_{G} \quad=$ gas phase heat transfer coefficient

$k_{G} \quad=$ gas phase mass transfer coefficient

$K_{L} \quad=$ liquid thermal conductivity

$N u_{G}=$ gas phase Nusselt numbers $\left(h_{G} d / K_{G}\right)$

$P_{B}^{*} \quad=$ vapor pressure of liquid film

$\mathrm{Pr} \quad=$ Prandtl number $(\nu / \alpha)$

$R \quad=$ gas constant

$r \quad=$ rate of reaction

Re $\quad=$ Reynolds number

$S c \quad=$ Schmidt number $(\nu / D)$

$S h_{G} \quad=$ gas phase Sherwwod number $\left(k_{G} d / D_{G}\right)$

$T=$ liquid temperature

$T_{G} \quad=$ gas phase temperature

$T_{R} \quad=$ temperature of cooling water

$U \quad=$ overall heat transfer coefficient for cooling water

$u \quad=$ axial velocity of liquid film

$y \quad=$ transversal coordinate (from wall toward the liquid free surface)

$y_{A} \quad=$ mole fraction of $\mathrm{SO}_{3}$ in the gas phase

$z \quad=$ axial coordinate

Greek Symbols

$\alpha \quad=$ thermal diffusivity

$\varepsilon_{D} \quad=$ eddy diffusivity

$\varepsilon_{H} \quad=$ eddy thermal diffusivity

$\varepsilon_{M} \quad=$ eddy viscosity

$\Gamma \quad=$ liquid loading

$\lambda=$ heat of vaporization for liquid film

$\delta \quad=$ liquid film thickness

$\mu \quad=$ liquid viscosity

$\nu \quad=$ kinematic viscosity of liquid $(\mu / \rho)$

$\rho \quad=$ liquid density

$\tau_{i} \quad=$ interfacial shear stress

\section{REFERENCES}

Davis, E.J., Venkatesh, S., 1979. Solution of conjugated multiphase heat and mass transfer problems. Chem. Eng. Sci., 34, 6: 775-787.

Johnson, G.R., Crynes, B.L., 1974. Modeling of a thin film sulfur trioxide sulfonation reactor. Ind. Eng. Chem. Process Des. Develop., 13, 1: 6-14.

Gutierrez-Gonzalez, J., Mans-Teixido, C., Costa-Lopez, J. 1988. Improved mathematical model for a falling film sulfonation reactor. Ind. Eng. Chem. Res., 27, 9: 1701-1707.

Henstock, W.H., Hanratty, T.J., 1976. Interfacial drag and the height of the wall layer in annular flows. AIChE J., 22, 6: 990-1000.

Lamourelle, A.P., Sandall, O.C., 1972. Gas absorption into a turbulent liquid. Chem. Eng. Sci., 27, 5: 1035-1043.

Levich, V. G. , 1962. Physiochemical Hydrodynamics. Prentice Hall, Englewood Cliffs, New Jersey: 691.

Ludwig, E.E., 1983. Applied Process Design for Chemical and Petrochemical Plants. 2nd Ed., Vol. 3, Gulf Publishing Co. Houston: 71.

Reid, R.C. Prausnitz, J.M., Poling, B.E., 1987. The Properties of Gases and Liquids. 4th Ed., McGraw-Hill, New York: 598-614.

Riazi, M.R., Faghri, A., 1986. Effect of the interfacial drag on gas absorption with chemical reaction in a vertical tube. $A I C h E J ., 32,4: 696-699$.

Riazi, M.R., 1986. Estimation of rates and enhancement factors in gas absorption with chemical reaction and gas phase mass transfer resistances. Chem. Eng. Sci., 41, 11: 2925-2929.

Van Driest, E. R., 1956. On turbulent flow near the wall. J. Aero. Sci., 23: 1007-1015. 